\title{
Rescue of Heretics by Psychological Counseling and Therapy
}

Yan Meifu

Department of Psychology, Wuhan University, Wuhan, Hubei, China

\begin{abstract}
Heretic rescue is a major part of anti-heresy activities, in which psychological counseling and therapy play a unique and irreplaceable role. This paper illustrates the role of psychological counseling and therapy from perspective of domestic reality of heretic rescue, describes difficulties and challenges faced in carrying out psychological counseling and therapy among heretics as well as available theories and methods in psychological counseling and therapy for heretic rescue.
\end{abstract}

Key word: Psychological counseling and therapy, heretic, rational-emotive therapy, cognitive therapy, psychoanalytic therapy.

\section{Psychology has Inherent Advantages in Rescuing Heretics}

Heresy issues cannot be belittled for various governments in the world and there are many governmental and civil organizations all over the world adopting methods of psychological consultation organization establishment to rescue them out of heresy. Therefore, that how to service the special categories with mental crisis-heretics becomes a social issue to be studied urgently for psychological workers especially working on psychological counseling and therapy.

The so-called beliefs (xinnian in Chinese) are commonly known as belief (xinyang in Chinese), a tendency in consciousness, trust, respect and reverence of a person for one theory or doctrine, referring to a sort of conscious trend that a person has firm certitude and deep trust in some ideas, also preparing to put them into practice. It is a kind of cognitive activity psychologically. The type of a person's beliefs is closely associated with his cognitive experience and relevant dreams for the future. Belief is the basis of self, a kind of high psychological activity of human, determining

Corresponding author: Yan Meifu, professor, research field: buddhist culture. individual behaviors. It reflects the yearning and pursuit of a person, or a group, strong spirit prop of the existence and movement as well as strength source and behavior driver. It can be divided into political belief, theoretical belief, moral belief and religious belief and so on and it is very difficult to change once it is formed and reinforced, different from general concepts. Belief gives people tremendous force, enabling people's will still to be like a rock after they share hardship, or put it into practice even at the cost of their lives. Meanwhile, it is also long-lasting, enabling people's heart to be constant without changes even within decades; belief is to be studied from perspective of ethic philosophy while psychological mechanism and influencing factors in belief formation and change is the working object in psychological counseling and therapy. The rational-emotive therapy created by American famous specialist in psychological counseling and therapy, Albert Ellis is aimed at changing unreasonable ideas of the crowd with psychological barriers. As for mind control, it is psychological control essentially. Therefore, rescue of heretics based on psychological counseling and therapy is making use of its advantages.

AFF (American Family Foundation, built in 1979, non-profit and tax exempt research center and educational organization with a duty of rescue those 
people constrained directly or indirectly by heresy) and American Wellspring Rehabilitation and Advisory Center once replaced term 'heresy' with 'psychological abuse group' and specially set standards for heresy organization research in group psychological abuse. This replacement and standard establishment fully shows psychological counseling and therapy plays significant role in solving dead-weight and serious issue of heresy; that psychological counseling and therapy plays a unique and irreplaceable role in the fight with heresy has been involved in many domestic literature. Many principles of psychological counseling and therapy accumulated in this discipline has their own disciplinary advantage in revealing the psychological process of the founder of heresy in controlling the heretics mentally, illustrating the heretics' psychological mechanism in their ecstasy of heresy and exploring the deep psychological source of heresy in inducing the heretics' mental pathology and personality disorder.

\section{Role of Psychological Counseling and Therapy in Rescue of Heretics}

\subsection{Psychological Counseling and Therapy can Help}

\section{Heretics Overcome Their Sufferings}

People always feel pain mentally when suffering setbacks, for example, their heart cannot be smoothed and healed, or they fail in finding a way out due to bewilderment mental, or they cannot be cured physically or mentally (for example, suffering from rheumatoid, diabetes mellitus, bronchial asthma or other physical illness, or such mental illness as psychathenia and depressive illness). It can be said that various pains exist among all heretics to some extent. Those wallowing in pain are always more access to heresy because they don't see the well-being of happiness, failing in finding a bright road due to narrow insight as heresy will provide them a road out of the pains: firstly, it can cure various diseases, enabling them to enjoy happiness and forever live without diseases and pains; secondly, it can bring them into another space with God full of only happy rather than pains.

Therefore, relevant methods can be adopted in psychological counseling and therapy to remove heretics' irrational belief of pains - absolute view of pain by letting them realize pains are not totally negative but also with positive meanings and value, realize they would not learn the world clearly or grasp the concept of happiness if without pains, or have such a magnetic personality with firmness, tolerance, perseverance and greatness more as the history of human is just the process from pains to happiness and letting them see human's persistence in fighting with diseases, not listen to information on heresy, or delude themselves that human can be cured in all disease within a morning without death.

\subsection{Psychological Counseling can Help Reduce Heretics' Fear in Mind}

Fear is potential focus hiding deep in human mental and it will be induced once in a proper situation, becoming a breakthrough for various heresies to attract the heretics. Many heretics are not willing to break away from heresy or return to be heretics after being rescued, in which the focus of fear plays a significant role. The feeling of fear is not totally come from the environmental conditions as a half-year old child can also fear when facing to cliffs simulated by human (see 'visual cliff' experiment in psychology). All human have fear in a situation or facing to something troublesome beyond their ability. It is inherited as human in ancient age had fears when facing nature's magic and death, or in an irresistible situation, product of obscurantism and ignorance and reflection of human confusion of loving the world but being unable to live forever. As the saying goes, ants cherish their lives, let alone me. Therefore, fears exist among everyone. But heretics are of more fear than ordinary ones as they are afraid of revenge from reality and gods after breaking away from or betrayed heresy on one hand, and they trust the apocalyptic thoughts and the Destruction of the Earth 
propagandized by heresy, thinking the doom of mankind including them is coming on the other hand. In addition, they are more afraid of death than others while fears of the later fear only exist subconsciously, which even sometimes unknown to them with reflection of fearing diseases and pains brought by diseases in the level of consciousness. Because of suffering from diseases, they are still afraid of death deep inside themselves although sometimes say 'let me die!'

Just because of this, they can be more easily attracted by the boasting and promise that heresy carriers can be cured if they believe in gods and pray, and become a heretic when being able to be cured after a long time or being limited by their own economic conditions. Thereafter, they will become isolated from the world and face to their own death bravely. At this time, that whether they can revive after death or whether to make their soul live forever becomes the only issue to worry. Therefore, heretics express their loving the world and refusing to die with an abnormal method. Psychological counseling and therapy can help heretics reduce or estimate fears curbed into subconscious long time ago after hiding mentally. Relevant psychotherapy familiar in modern psychology makes them understand by effective input approaches: firstly, death is unavoidable; secondly, death is not to be feared but pains before death can be reduced; thirdly, resurrection after death said by heresy and living forever of soul are both deceptive and psychology (soul in ancient Greek)' dependency on body (the nervous system), especially that psychology (soul) will disappear after the death of body has been proved based on application of experiments and true in psychology; fourthly, psychology has proved that fear is brought about by cognitive activities, that is the so-called emotions come from intelligence. Therefore, fear of death will be reduced or estimated if the irrational belief infused by heresy is abandoned with changes in misconceptions of death.
2.3 Counseling and Therapy can Help Estimate Heretics'Resentment and Rage in Mind

In general, resentment and rage are reflection of hopelessness, an emotional state of daring not anger or speaking out when facing to unfairness or being oppressed and mental response of the weak in facing to helplessness and misfortune. Most heretics are weak without power, advantage in economy, position and dignity, and they are always deprived of opportunities with ignorance in their rights, making them suppress inner dissatisfaction and discontent, but fail finding out approaches to let off them based on frightening and constraint of laws and morals. Then heresy comes. It uglifies the current society, attacks mankind, instigates and strengthens such resentment and rage of the minority as much as possible on one hand, and provides two channels to reduce them on the other hand: firstly, stirring and leading the heretics to attack, abuse the party and government, secondly, promising to guide the heretics to heaven without conflicts and contradictions, braging greatly and selling the ticket to heaven at low prices.

Of course, psychological counseling and therapy also didn't not advocate suppressing inner resentment and rag, but instead using the unique theory and method to help reduce the heretics' pains, different from heresy: firstly, helping heretics change their irrational belief and letting them realize absolute fairness and equality don't exist, that is, 'heaven', 'Falun World' the founder of heresy describe don't exist, only imaginary with psychological counseling an therapy method; secondly, fairness and equality are only a kind of subjective feeling and experience of mankind as people can regard the events with original fairness and equality as the unfair due to different aspects and undergrounds of observation and feeling, further making many have resentment and rage because of feeling unfair and unequal, but wrong; thirdly, all human have a sort of unhealthy psychological trends: liking overestimating their own contribution and underestimating return of their efforts. 
On the contrary, they are always overestimating contributions of others, especially the ones around, but overestimating their return of efforts, making many heretics resent the current society. Estimation will be expected in their negative moods once the operation of psychological counseling proves and makes the heretics realize their resentment and rage are from such psychological trends with relevant fact.

\subsection{Heretics' Void and Helplessness can be Reduced after Their Being Out of Heresy by Psychological Counseling}

Void is a sort of inner experience after suffering a major loss: emptiness will appear mentally if the party's pursuit such as dream, prospect, career, achievement and happiness have been all died forever; helplessness refers to a sort of inner experience that a person loses motivation and desire of striving for diastasis and stops striving and struggling totally after suffering setbacks or hits as the continuous ones are still unavoidable even based on various endeavors or even struggle. In reality, for those who have psychological emptiness, helplessness and anxiety due to their illness, poor life, betrayal and alienated affection, failure and setbacks in career, bleak future with helplessness, they cannot see any sign or hope in their happiness except misfortunes in front.

Heresy always fills the void and attracts people to give up everything in the world by its pursuit of another world of plenty, happy life with fortunes for purpose and driver: money, love and misfortunes and live to the fine goal pictured by heresy never saying die. However, rescue also awakens them to reality from the dream and finally enables them to understand that all pictured by heresy is deceptive trick. Therefore, they after rescue again return to the original reality making them empty, helpless, and desperate in heresy and such feelings are just in fact a return of their psychology before their participation in heresy. At this time, psychological workers are required urgently to carry out psychological counseling and therapy among them with cognitive therapy and rational-emotive therapy and so on in order to help them correct some of their irrational beliefs intellectually, discover self-potential and learn to face to misfortunes and pains in reality.

\section{Difficulties in Carrying out Psychological Counseling and Therapy among Heretics}

It is significantly difficult to carry out psychological counseling among the ones extremely obsessed with heresy, intensively shown in many aspects:

\subsection{Norms and Principles of Psychological Counseling are Challenged}

As a branch of psychology, psychological counseling and therapy has developed certain major strict rules for psychologists, but among which some are challenged when psychological counseling and therapy is applied to heretics:

(1) Principle of 'value neutrality'. This principle of psychological counseling shows there is no absolutely correct standard and law of value and known to the public at present, even such a view of value like 'human should have heart of the benevolence' is only accepted by me and the ones with similar beliefs with me and there is no way to prove its universal meaning. Of course, various endeavors in building absolute standard of value from perspective of concepts such as the will of deity, human conscience and human biological nature have been made in history, but all in vain. Therefore, it is illegal morally for psychologists to impose their own values on their clients and urge them to give up their own values. Then the principle of value neutrality is advocated. However, can it be also available to those heretics for psychological counseling? It is of course not as one major purpose of psychological counseling among heretics is to destroy their wrong values due to irrational beliefs and replace the values in accordance with our social ones with their old ones. Therefore, that how to change heretics' values by counseling based on the relevant principle 
of value neutrality becomes a big challenge in psychological counseling for heretics.

(2) Principle of voluntary and autonomy of the party (referring to heretics here).

One outstanding characteristic of therapy in psychological counseling different from other is medication treatment is not forced into effect as we can give a patient with the defense medicine or injection, making the treatment still work, but we cannot carry out psychological counseling and therapy for the one unwilling with hostility and doubts to psychological counseling and therapy as well as psychologists and obtain any effects in psychological counseling and therapy. The party's indifference, guard, non-cooperation and even hostility make counseling almost impossible. Therefore, psychological counseling shall be in accordance with principle of the party's voluntary and autonomy, that is every counseling is carry out based on the party's being willing to change in himself and psychologists cannot urge the party to accept or maintain the psychological counseling with any means. Obviously, it is relatively hard to implement this principle in counseling of heretics. After the heretics believe in heresy, they always feel good about themselves physically and mentally and it is impossible for them to be initiative and willing to accept psychological counseling because of suggestion from the founder of heresy. It is no doubt that it is of major difficulty in carrying out psychological counseling for heretics based on the principle of voluntary and autonomy.

\subsection{No Common Language}

Psychological counseling is implemented based on language and one major difficulty in psychologists' communication with the heretics is language barrier as what the heretics use is heresy language produced by the founder of heresy special for heretics. The founder of heresy controls the heretics' mind step by step just by confusion and subtle penetration of this language. This can be seen clearly from the rescue of Falun heretics, the heretics using Li Hongzhi's words or the original texts in Dhammacakka-pavattana in their communication with their rescuers are everywhere. In another word, those people have even lost the ability of using the common language and their linguistic devices no matter in deep structure or surface structure have also been replaced with those special heresy language. Therefore, the first issue for psychologists in their developing psychological counseling is language barrier, that is, in another word there is no common language between psychologists and the heretics consulting.

\subsection{No Common Mode of Thinking}

Heresy language gives birth to heresy thoughts which makes the heretics' thinking ability deteriorate and better serve the founder of heresy. All phenomena and issues can be solved and explained by heresy thinking in term of heresy. For example, diseases are a reflection of Karma and having diseases is eliminating. The worldly parents are not the real parents and the phenomena of being undutiful for parents and ill-treating children can all be explained with the wheel of karma, even the practitioners' killing can be help. Fu Yibin still proudly said, 'view from perspective of Falun is really breathtaking' after killing his father and wife. Perspective of Falun in his words is reflection of heresy thinking. Mode of heresy thinking existing in the heretics' mind again provides thinking barrier between psychological counseling and the heretics. The barriers in language and thought between psychological counseling and the heretics make it hard to implement psychological counseling among the heretics.

\section{Theories and Methods Commonly Used in Psychological Counseling and Therapy for the Heretics}

At present, methods of psychological counseling and therapy have been hundreds. Considering the particularity of heretics as an object, many of them are 
not available. For example, people-oriented therapy in thought of psychological counseling and therapy coming from human psychology and the relevant communication and analysis therapy are both suitable. Such kind of theory and method overly focus the consulted objects' inner potential of self-improvement and they would think them the best experts with methods of solving their problems while the consultants always negative overly and obviously, or even controlled by the former sometimes. The available theories and methods of psychological counseling and therapy are mainly:

\section{1 (REBT) Rational Emotive Behavior Therapy}

REBT was a method of psychological counseling and therapy developed by an American, Albert Ellis between the late 1950s and the early 1760s, which will have its advantages and mitigating virtue in theory and method if applied in psychological counseling and therapy for the heretics. Firstly, in theory, this therapy thinks that various psychological barriers of mankind are all from bad changes in moods due to cognitive distortion while cognitive distortion is brought about by unreasonable beliefs due to the irrational mode of thinking, and it is necessary to change a person's unreasonable beliefs first for removing his psychological barriers. Just as mentioned above, repetition appears in the heretics after being changed or they refuse to be rescued is rooted in that the unreasonable beliefs infused by heresy are not be cleared. Seen from this, rational-emotive behavior therapy applied in psychological counseling and therapy for heretics is of strong target; secondly, in operation, this therapy is of good practicability in its Socratic spiritual art of practice midwifery fighting with the unreasonable belief, a smart and skillful debating skill and art where the party's unreasonable beliefs are promoted in change by positive questions. This debating method appears with respect and politeness, but aggressive by its asking again and again, making the opposite side have no choice but to admit the absurdity in his beliefs. We are able to promote the elimination of the opposite side's unreasonable beliefs in mind more quickly if using this method skillfully in psychological counseling and therapy.

\section{2 (CT) Cognitive Therapy}

It is a method of psychological counseling and therapy developed by an American, A.T Beck in 1960s and the reasons for its going for rescuing the heretics are: firstly, the principle of this therapy can reasonably explain obsession of the heretics. From perspective of cognitive therapy, psychological barriers of mankind are rooted in their ordinary psychologically cognition process and mankind are inclined to make a kind of mistake, unique logic error, for example, they have flawed thinking, jumping to incorrect conclusions according to incorrect or insufficient information, or confounding fantasy with reality. Distorted cognitive form refers to arbitrary inference, selective out-of-context, excessive generalization, extreme thinking, exaggeration and belittling, etc in understanding the world. And then negative automatic thoughts are produced. Thereafter, they always treat pains, life and society negatively, and constructed wrong cognitive scheme in mind, which guides them in further cognition of life and society in turn when being confused by heresy and having a plausible understanding of it. Secondly, cognitive therapy proposes a set of therapeutic method and technology for correcting negative automatic thoughts and wrong cognitive schemes, including reduction to absurdity, cost-benefit analysis and authenticity testing, etc. They are not specially designed for heretic rescue, but we can make proper revision and modification in them according to characteristics of rescue in order to be available to it.

\subsection{Psychoanalysis}

It is a method of psychological counseling developed by Austrian psychiatrist Sigmund Freud 
and the reasons for its being available to psychological counseling and therapy are it thinks stupid heretics' highly obsession with heresy and the origin hard for conversion as well as the driver are rooted deep in consciousness-subconsciousness, making psychoanalysis also called deep-psychology, dynamic psychology. All endeavors in rescue will be in vain if the rescuers fail in obtaining deep insight into the reasons and driver of the heretics' obsession with heresy. By this method, psychologists will be able to keenly discover the real reasons for heretics' obsession with heresy according to their usual words and behaviors, all problems being solved. The heretics will become awake suddenly from their dreams only if they are helped to rise to the level of consciousness in subconsciousness, saying goodbye to heresy consciously.

\section{References}

[1] Jiang Guangrong, Theories and Practices of Psychological Counseling, Higher Education Press, 2005.

[2] Yang Hongfei, Principle of Psychological Counseling,
Self University Press, 2006.

[3] Zhu Cuiying, etc. Theories and Skills of Psychological Counseling, Hunan Science and Technology Press, 2007.

[4] Hay, P. J., Claudino, A. M., Touyz, S., and Elbaky, G. A. 2015. "Individual Psychological Therapy in the Outpatient Treatment of Adults with Anorexia Nervosa." Cochrane Database of Systematic Reviews 2015 (7).

[5] Ramírez, N. H., and Díaz, C. A. G. 2009. "Brief Therapy: An Alternative for Effective Psychological Intervention." Avances En Psicologia Latinoamericana 27 (1): 165-76.

[6] Erik, B., and Nielsen, L. M. 1983. "Psychotherapeutic Drugs: A Brief Review of Their Effects on Psychological Processes." Scandinavian Journal of Behaviour Therapy 12 (4): 211-20.

[7] Sun, B., Tian, Y., Sun, H., and Wang, W. 2016. "Self: A Perspective from Psychological Counseling and Therapy." Advances in Psychological Science.

[8] FU Yan-Fen. Theoretical Analysis of Psychological Counseling and Therapy Introduced into China in Recent Thirty Years. Health Medicine Research \& Practice, 2011.

[9] He, L. 2010. "Application of Psychological Counseling and Therapy to the Preoperative Psychological Intervention on the Patients with Surgery at the Appointed Time." Journal of Qilu Nursing.

[10] Gustad, J. W. 1955. "Psychological Counseling." Journal of Counseling Psychology 1955 (4): 308-9. 